\title{
Economics of Obesity, Energy Intakes, and Physical Activity among Adults in Appalachia, USA
}

\author{
Janaranjana Herath $^{1, *}$, Cheryl Brown², David Hill ${ }^{1}$ \\ ${ }^{1}$ Tillman School of Business, University of Mount Olive, Mt Olive, USA \\ ${ }^{2}$ Davis College of Agriculture, Natural Resources and Design, West Virginia University, Morgantown, USA \\ *Corresponding author: samanjanaranjana@yahoo.com
}

Received June 26, 2014; Revised August 13, 2014; Accepted September 09, 2014

\begin{abstract}
Many research outcomes highlight the use of behavioral changes to combat obesity. This study attempts to examine and discuss the potential use of physical activity and less energy intakes in mitigating obesity among the adults in Appalachia, USA. Within the context of utility theory and behavioral aspect of energy balances of an individual, a system of simultaneous equations with three endogenous variables; decision to reduce energy intakes, time engaged in physical activity and Body Mass Index (BMI) were used for the analysis. The results highlight the potentials of weight control by reducing energy intakes and engaging in more physical activity. Importantly, the results emphasize that elderly individuals are less likely to engage in physical activity and reduce energy intakes to control BMI at the same time. The individuals with high BMI values are more likely to reduce energy intakes than engage in physical activity. The male are more likely to engage in physical activity to control obesity than reducing energy intakes while the female are more likely to reduce energy intakes than engaging in physical activity. Higher income generation, job opportunities, service of health professionals, and availability of recreational facilities play a key role in changing behaviors for controlling obesity.
\end{abstract}

Keywords: Appalachia, obesity, energy intakes, physical activity

Cite This Article: Janaranjana Herath, Cheryl Brown, and David Hill, "Economics of Obesity, Energy Intakes, and Physical Activity among Adults in Appalachia, USA." American Journal of Public Health Research, vol. 2, no. 4 (2014): 176-181. doi: 10.12691/ajphr-2-4-8.

\section{Introduction}

Obesity is ranked among the leading global public health problems [1]. It is considered the biggest health problem in the world in the $21^{\text {st }}$ century; approximately half a billion people worldwide are affected by either obese or overweight [2]. In the United States, obesity is a major health problem, and approximately 34 percent of the U.S. adult population is obese (over 72 million people), with nearly 67 percent of adults overweight $[3,4]$. If the current trend of obesity continues, 50 percent of the U.S. population will be obese in 2030 [5]. Two U.S. studies, Behavior Risk Factor Surveillance System (BRFSS) and the National Health and Nutritional Examination Survey (NHANES) show that obesity in the United States will increase from its current level of 31.3 percent to 42.8 percent in 2018 [6,7].

Several diseases, such as heart disease, diabetes (type II), hypertension, cancer, arthritis, asthma, and some psychological disorders (like depression) are linked with obesity $[8,9,10]$. Moreover, obesity increases the risk of premature mortality and nearly 300,000 annual deaths are associated with obesity in the United States $[1,10]$. Meanwhile, the World Health Organization (WHO) reports that non-communicable chronic diseases will become the predominant cause of morbidity and mortality in the near future, and those diseases will probably be responsible for about two-thirds of all disease costs by the year 2020 [11].

The economic burden associated with obesity is high. Expenditures on health have outpaced economic growth in many countries, putting pressure on government budgets [12]. Obesity accounts for 2 to 9 percent of the total health budget in high-income countries, excluding the cost of all obesity-related conditions. Hammond and Levine (2010) identified four major categories of the economic impacts associated with obesity: direct medical costs, productivity costs, transportation costs, and human capital costs [13]. In 1998, the United States spent $\$ 78.5$ billion on medical costs related to obesity [14]. According to the U.S. Department of Health and Human Services, the annual cost of obesity was $\$ 147$ billion in 2008 and people who were obese had annual medical costs that were $\$ 1,429$ higher than the cost for people of normal body weight [15]. According to the BRFSS and NHANES data the cost of obesity could increase up to $\$ 343.9$ billion in 2018 in the United States [6,7]. The data indicate that if the prevalence of obesity at today's level could be halted, the United States could save $\$ 821$ per adult in 2018; that is a total of $\$ 198$ billion. At present, the overall annual cost of being obese is $\$ 2,646$ for an obese man and $\$ 4,879$ for an obese woman [5]. However, the magnitude of health impacts depends on the levels of obesity-related diseases, socioeconomic and behavioral characteristics of individuals 
and environmental and geographical characteristics of a particular region [16,17,18,19].

High obesity is linked with more disease and less quality of life $[8,9]$. It leads to high economic losses to individuals and to society. Individuals who have health problems due to obesity have to bear the direct costs for medication, physician visits, hospital stay, etc. Obesity reduces efficiency and productivity of employees through work absenteeism, early retirement, and premature death. Also, it adds additional costs to the healthcare system $[6,7]$. Thus, the main objective of this study is to examine the potentials of less energy intakes and more physical activity in controlling obesity among adults in Appalachia, USA.

The paper is organized into six sections. Section 2 provides background information of the study. Section 3 explains the methodology and data sources. Section 4 discusses empirical results and analysis. Section 5 presents conclusions and policy suggestions.

\section{Background information}

\subsection{Defining Obesity}

Obesity is defined in terms of Body Mass Index (BMI). BMI is a proxy for human body fat based on an individual's weight and height. BMI is generally defined as the individual's body weight divided by the square of his/her height and produces a unit measure of $\mathrm{kg} / \mathrm{m}^{2}$. Since the 1980s the World Health Organization (WHO) has used BMI as the standard measure for recording obesity. According to U.S. National Institute of Health (NIH) guidelines, from 25 to $29.9 \mathrm{BMI}$ is defined as overweight, and from 30 to $34.9 \mathrm{BMI}$ is defined as obese [20]. When the value is more than 35 BMI, it is normally called 'severe obesity' (Table 1).
The Appalachian Region consists of 420 counties in 13 states: New York, Pennsylvania, Ohio, Maryland, West Virginia, Kentucky, Virginia, North Carolina, Tennessee, South Carolina, Georgia, Alabama, and Mississippi. The region has relatively homogeneous characteristics of topography, demographics, and economic background [21]. The main economic activities in the region are related to mining, forestry, agriculture, chemical industries, professional service, and manufacturing sector [22]. Of 420 counties of the region, 96 counties were considered economically distressed, 90 counties are at risk, and 219 have transitional economies [22]. The region is facing a lack of human, financial, and technical resources due to its geographic isolation, disproportionate social and economic distress, low household incomes, and a declining tax base. The Appalachian region is home for nearly 24.8 million people, and its population growth from 2000 to 2008 was slower than the national rate [23]. In 2009, Appalachian Regional Commission (ARC) classified the region into five sub-regions: Northern, North Central, Central, South Central, and Southern (Figure 1). The highest population is reported in Northern Appalachia while the lowest is in Central Appalachia. In many parts of Appalachia young people are moving out and retirees are moving in [21]. According to the economic overview of Appalachia, the average unemployment rate is higher than the national rate in Appalachia, and the per capita personal income, per capita investment income, and education level, are lower than the national averages [22].

\begin{tabular}{cc}
\multicolumn{2}{c}{ Table 1. Classifications of obesity } \\
\hline BMI & Classification \\
\hline$<18.5$ & underweight \\
$18.5-24.9$ & normal weight \\
$25.0-29.9$ & overweight \\
$30.0-34.9$ & class I obesity \\
$35.0-39.9$ & class II obesity \\
$\geq 40.0$ & class III obesity \\
\hline
\end{tabular}

Source: National Institute of Health (1998).

\subsection{Study Area}

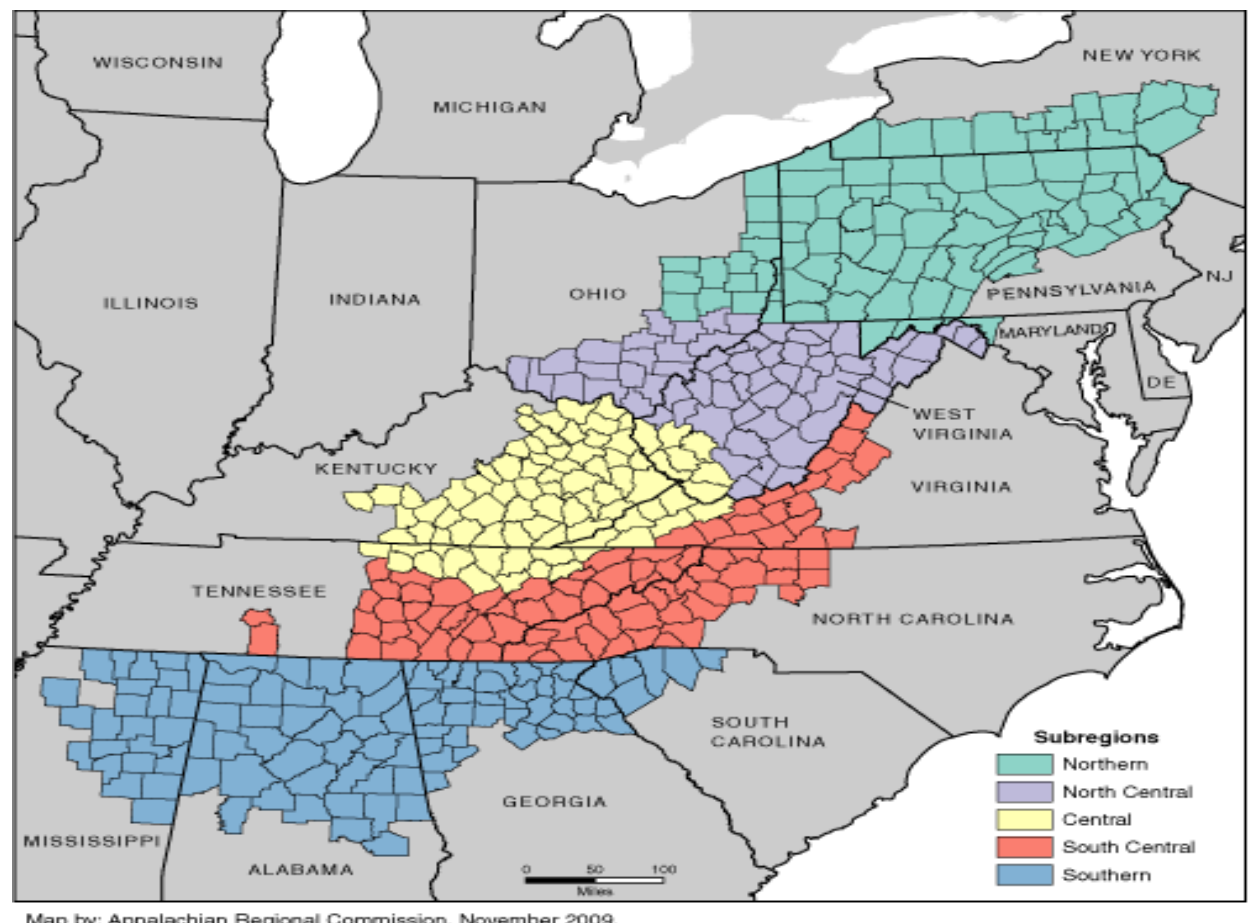

Figure 1. Map of the Appalachian region, 2009 
Appalachia reports high rates of obesity, serious diseases, and higher mortality rates, than national levels [21]. According to Wewers et al. (2006) 44 percent of the Appalachian population is obese with the highest rate reported from southeast Appalachia. One out of every three adults is considered overweight and roughly 10 percent of the population is suffering from diabetes, which may be highly related with obesity [24]. According to the morbidity and mortality report of the CDC, the prevalence of obesity (more than 31 percent) and diabetes (more than 10.6 percent) are higher in the states of West Virginia, Tennessee, Kentucky, Mississippi, Louisiana, Alabama (middle), Georgia (south), and the coastal regions of North and South Carolina than the national average [25]. Poverty associated with poor diets and sedentary life styles seem to be the main reasons behind this high obesity $[21,25]$.

\section{Methodology}

The behavioral aspects of obesity indicate obesity as a result of an energy imbalance between energy (calories) consumed and energy (calories) expended for a particular time period. Thus, obesity related morbidity, mortality and costs can be reduced through preventive behaviors aimed at reducing obesity [26]. Within the context of utility theory, an individual would take action to reduce obesity, which derives a 'disutility' through his/her market behavior of goods and services purchased or consumed, together with his/her own time utilization to physical activity to expend calories [27]. This supplies a framework to examine the issues of energy intakes and energy expenditure on reducing obesity using a set of simultaneous equations, considering the interdependence of energy intakes, physical activity, and obesity. A system of equations estimates all the identified structural equations together as a set. The most important advantage of this method is to have a small asymptotic variance. Three-stage least squares is consistent and generally more efficient than a two-stage least squares (2SLS) estimator [28]. Thus, a 3SLS analysis is conducted based on individual-level data of the region.

The first dependent variable, $\mathrm{CIT}_{\mathrm{i}}$, reflects the decision of individual i to reduce his/her energy intakes or the calorie intakes. When $\mathrm{CIT}_{\mathrm{j}}$ equals 1 that individual has decided to reduce energy intakes. The second equation, $\mathrm{PAC}_{\mathrm{i}}$, represents the number of minutes engaged in physical activity by individual i. The physical activity is defined as any bodily movement produced by skeletal muscles that require energy expenditure and here it is the time engaged in both moderate and vigorous physical activity. The third dependent variable, $\mathrm{BMI}_{\mathrm{i}}$, is the current value of the body mass index of individual I, which indicates the idea of obesity. $D_{j i}$ represents the $j^{\text {th }}$ disease of the $\mathrm{i}^{\text {th }}$ individual, which appears as a qualitative independent variable equal to one if the individual has the disease and zero otherwise. All other variables that represent socioeconomic factors (SF), behavioral factors (BF), and environmental factors (EF) are specified for each individual.

(1) $\mathrm{CIT}_{\mathrm{i}}=\mathrm{f}\left(\mathrm{BMI}_{\mathrm{i}}, \mathrm{PAC}_{\mathrm{i}}, \mathrm{D}_{\mathrm{ji}}, \mathrm{SF}_{\mathrm{i}}, \mathrm{EF}_{\mathrm{i}}, \mathrm{BF}_{\mathrm{i}}\right)$

(2) $\mathrm{PAC}_{\mathrm{i}}=\mathrm{g}\left(\mathrm{BMI}_{\mathrm{i}}, \mathrm{CIT}_{\mathrm{i}}, \mathrm{D}_{\mathrm{ji}}, \mathrm{SF}_{\mathrm{i}}, \mathrm{EF}_{\mathrm{i}}, \mathrm{BF}_{\mathrm{i}}\right)$

(3) $\mathrm{BMI}_{\mathrm{i}}=\mathrm{h}\left(\mathrm{CIT}_{\mathrm{i}}, \mathrm{PAC}_{\mathrm{i}}, \mathrm{D}_{\mathrm{ji}}, \mathrm{SF}_{\mathrm{i}}, \mathrm{EF}_{\mathrm{i}}, \mathrm{BF}_{\mathrm{i}}\right)$,

The equations to be estimated can be expressed as:
(4) $\mathrm{CIT}_{\mathrm{i}}=\alpha_{0 \mathrm{CIT}}+\alpha_{1 \mathrm{CIT}} \mathrm{BMI}_{\mathrm{i}}+\alpha_{2 \mathrm{CIT}} \mathrm{PAC}_{\mathrm{i}}+\alpha_{3 \mathrm{C}} \mathrm{D}_{\mathrm{ji}}+$ $\sum \psi \mathrm{SF}_{\mathrm{i}}+\sum \delta \mathrm{EF}_{\mathrm{i}}+\sum \omega \mathrm{BF}_{\mathrm{i}}$

(5) $\mathrm{PAC}_{\mathrm{i}}=\alpha_{0 \mathrm{PAC}}+\alpha_{1 \mathrm{PAC}} \mathrm{BMI}_{\mathrm{i}}+\alpha_{2 \mathrm{PAC}} \mathrm{CIT}_{\mathrm{i}}+\alpha_{3 \mathrm{PAC}} \mathrm{D}_{\mathrm{ji}}$ $+\sum \psi \mathrm{SF}_{\mathrm{i}}+\sum \delta \mathrm{EF}_{\mathrm{i}}+\sum \omega \mathrm{BF}_{\mathrm{i}}$

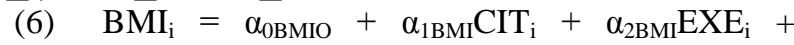
$\alpha_{3 \mathrm{BMI}} \mathrm{D}_{\mathrm{ji}}+\sum \psi \mathrm{SF}_{\mathrm{i}}+\sum \delta \mathrm{EF}_{\mathrm{i}}+\sum \omega \mathrm{BF}_{\mathrm{i}}$

where $\alpha_{0}$ is the intercept value of each equation, $\alpha_{1}$ and $\alpha_{2}$ values are the coefficients of each endogenous variable while $\psi, \delta$, and $\omega$ are coefficients of socioeconomic, behavioral, and environmental factors.

\subsection{Sources of Data}

Behavior Risk Factor Surveillance Systems (BRFSS) survey data collected by the Center for Disease Control and Prevention (CDC) for 2009 are the main source of data [29]. For the analysis, individual-level data are used. BRFSS data are collected from a stratified random sample through computer-assisted telephone interviewing by state health departments with the collaboration of the Center for Disease Control and Prevention (CDC). All data collected from BRFSS are at an individual level for adults 18 years of age and older. Data collection is conducted separately by each state. BRFSS interviews more than 350,000 adults each year for whole USA. The adjusted response rates vary by state and it was ranged between $39 \%$ and $67 \%$ in 2009. Data for access to healthcare facilities and recreation facilities are collected from the Bureau of Economic Analysis, and the U.S. Census Reports [30,31]. The analysis is done using the statistical package of STATA [32].

\section{Empirical Analysis and Discussion}

A system of simultaneous equations with three endogenous variables of the decision to reduce energy intakes (CIT), minutes engaged in physical activity (PAC) and Body Mass Index (BMI) was used for the empirical analysis. Of the total collected observations for 2009, 7,267 observations were used for the analysis after removing observations on pregnant individuals, reported missing data and seemed outliers. Due to inadequacy of data on energy intakes, and physical activity, counties of Maryland, Mississippi and Pennsylvania states were dropped from the analysis. Thus, it needs to be careful when generalizing results for these Appalachian counties.

Age of the individual (AGE), marital status (MARRIED), number of children in the household (NMBRKIDS), number of adults in the household (NMBRADULT), education level of some college or more (EDU), employment status (EMP), annual household income (INC), gender, race, presence of any obesity-related disease (ANYDISEASE): asthma, arthritis, cancer, diabetes, heart disease and hypertension were the socioeconomic variables used for analysis. Advice received on diet from doctors or any other health professional (DRADVICE), smoking (SMOKES), alcohol consumption (DRINKS), and the number of sleepless days in the previous month (SLEEP) was the behavioral variables used for analysis. Access to healthcare facilities (HLTHCRFAC), access to recreational facilities (RECREATION) and a regional dummy (NORTH) for the northern region of Appalachia were the environmental factors considered. The variable recreational facilities (RECREATION) include all available indoor and outdoor 
recreational facilities in a county. Northern, North Central and Central sub-regions of Appalachia were considered as north for the dummy variable (NORTH).

\subsection{Descriptive Analysis}

Descriptive statistics of the variables are shown in Table 2. Nearly 74 percent of the sample decided to reduce energy intakes and about 60 percent get advice on food and diet from their doctors or some other health professional. The average time an individual engaged in physical activity is 262 minutes per week. The average BMI value of the sample is 29.87, indicates the majority of the population is overweight or obese. The average annual income is just over $\$ 36,000$, but only 29 percent are employed. Of the total adult population, only 38 percent is male, indicating that the majority is female. Nearly 46 percent of the sample is educated at some college level or beyond. The mean value of education seems to be a bit high, but could be accepted when considers the mean age of the sample of 61. According to the Appalachian Regional Commission only 41.0 percent of the Appalachian population having some postsecondary education or higher compared with 51.8 percent of the nation. Of the total sample, 38 percent indicate suffering from at least one of the obesity-related diseases, and 21 percent live in the north of Appalachia.

Table 2. Descriptive statistics for obesity prevention analysis

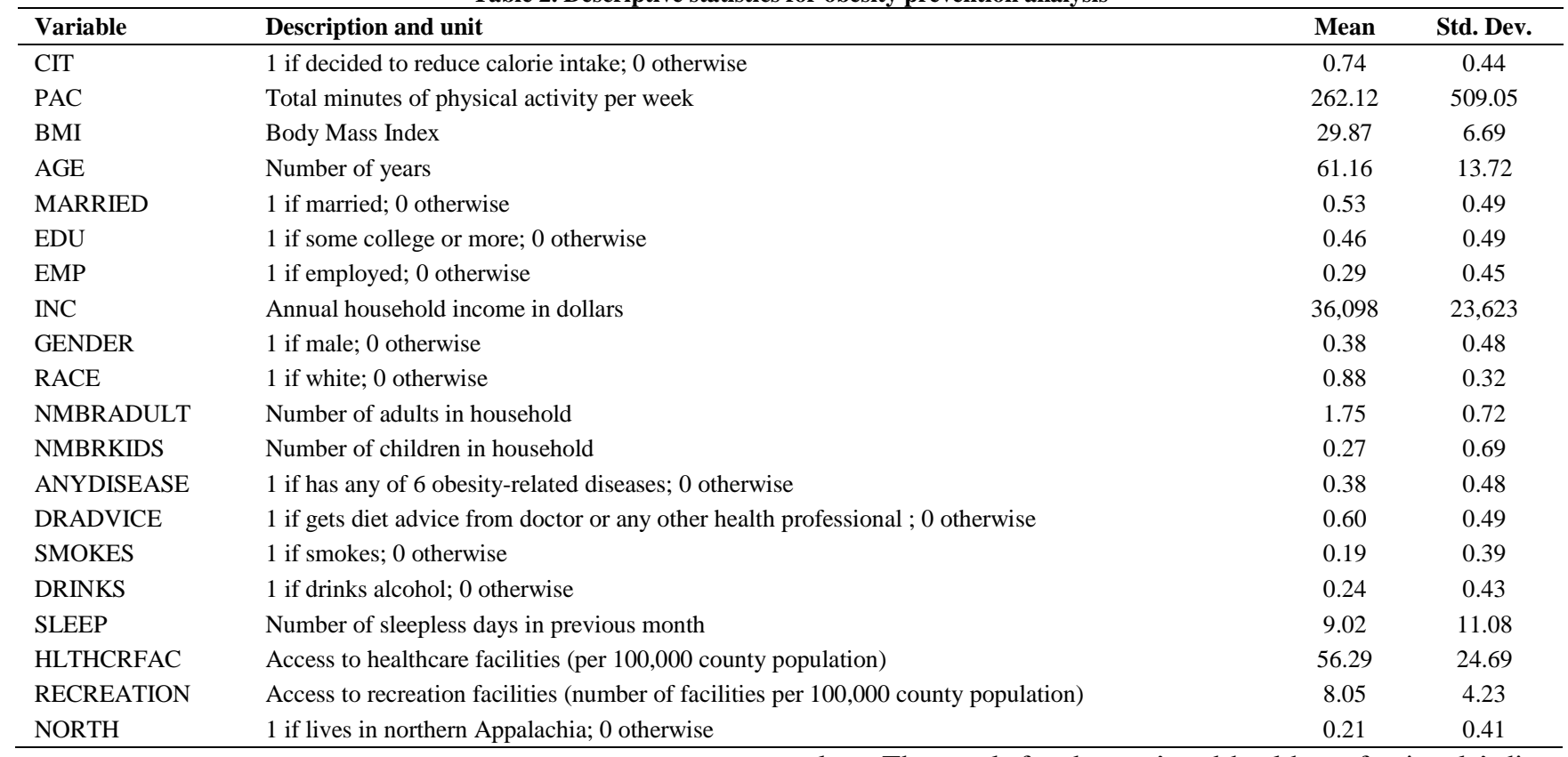

\subsection{Econometric Analysis}

The empirical results are presented in Table 3. While column 1 shows the variables used for the 3SLS analysis, columns 2 and 3 show results for the calorie reduction estimation; columns 4 and 5 present results for physical exercise, and columns 6 and 7 show results for BMI. Logged values of BMI were used for the analysis as it results statistically more significant estimations.

According to the results for energy reduction equation (CIT), physical activity (PAC) has a significant and a negative relationship with energy reduction. An increase in the time spends engaging in physical activity decreases the likeliness to reduce energy intakes. The BMI shows a significant and a positively relationship with the decision of reducing energy intakes. Thus, increases BMI increases the probability of deciding to consume fewer calories. Age has a significant and a negative relationship with energy intakes reduction, but the impact is minimal. According to the results, a female is 6 percent more likely to reduce energy intakes than a male. Also, results indicate that higher number of children in a household hinders the decision of reducing energy consumption. This may be associated with more food purchase or preparation with many members in the household. Annual household income indicates a significant and a positive relationship with decision of reducing energy intakes, but the value is low. The result for doctors' and health professionals' diet advice indicates that those who are advised to control their diet are 22 percent more likely to reduce energy intakes than others. This emphasizes the importance of the service of health professionals in Appalachia.

The results for the physical activity (PAC) equation show that those who have decided to reduce energy intakes for weight gain control engage in fewer minutes of physical activity per week than those who have not made this energy reduction decision. The significant and negative result for BMI indicates that when BMI value increases by one percent, engage in physical activity decreases by 0.017 percent. Though the impact value is minimal result implies that individuals with high BMI values tend to engage in fewer minutes of physical activity. The significant and negative relationship between physical activity and age shows that older individuals spend less time in physical activity. The significant and positive relationship between physical activity and education highlights that those with some college or more education spend more time on physical exercises than others. Thus, education helps in encouraging weight control. Nayga and Drewnowski and Specter emphasize that higher education lowers obesity rates as health promotion occurs through knowledge $[33,34]$. Cawley et al. show that the impact of decreased physical education classes in schools has increased the probability of students being overweight [16]. According to the results employed individuals 
engage in 38 more minutes of physical activity per week than the unemployed individuals. This may be associated with facilities available for employed in their working places, the type of their employment or having more time or affordability for resources for such activities. Income has a significant and a positive relationship with physical activity, but the impact is low. According to the results a male engages in 39 more minutes of physical activity a week than a female. While sleepless days negatively affect on time spend engaging in physical activity, access to more recreation facilities significantly increases minutes spend exercising. The results also indicate that individuals in northern Appalachia engage less in physical activity compared to the adults in the southern part. This might be due to less education, health issues, high unemployment rates and poverty associated with central and north central sub-regions.

According to the results for BMI equation (Log BMI), those who decide to intake less energy can reduce BMI by 13 percent. The significant and positive result for engage in physical activity and BMI indicates the potential of reducing BMI by increasing exercise. Age is negatively related to BMI, thus, increasing age by one year decreases BMI by 4.8 percent. The result has to be interpreted carefully within the mean age of the sample of 61 years. In a study in West Virginia, Amarasinghe et al. found that the risk of obesity increases at a lower rate with age. Income shows significant results, but the impact is low [35]. The significant and negative relationship between BMI and gender implies that a male has a 33 percent lower BMI value compared to a female. The result for race indicates that a white individual has 2 percent lower $\mathrm{BMI}$ than to a non-white individual. Both results indicate that non-white women have high value of BMI and they are more susceptible to be obese. Presence of any considered obesity-related disease increases BMI by 6.2 percent. The result is supported by the findings of Herath et al. (2013) which found the positive impacts of diabetes and arthritis on obesity [36, 37]. Both smoking and drinking have a negative relationship with BMI; that smoking decreases BMI by 7.5 percent, while drinking decreases BMI by 4.3 percent. This is supported by the findings of but literature supplies different results too [19].

Table 3. Results for system of equations for obesity prevention analysis*

\begin{tabular}{|c|c|c|c|c|c|c|}
\hline \multirow{2}{*}{ Variable } & \multicolumn{2}{|c|}{ CIT } & \multicolumn{2}{|c|}{ PAC } & \multicolumn{2}{|c|}{ BMI } \\
\hline & Coefficient & $\mathrm{P}>|\mathrm{Z}|$ & Coefficient & $\mathrm{P}>|\mathrm{Z}|$ & Coefficient & $\mathrm{P}>|\mathrm{Z}|$ \\
\hline CIT & & & $-0.9661^{* * *}$ & 0.00 & $-0.1273^{* * *}$ & 0.00 \\
\hline PAC & $-0.0261 * * *$ & 0.05 & & & $-0.2569^{* * *}$ & 0.00 \\
\hline BMI & $0.6323^{* * *}$ & 0.00 & $-1.7702^{* * *}$ & 0.02 & & \\
\hline AGE & $-0.0020 * * *$ & 0.01 & $-0.0365^{* * *}$ & 0.00 & $-0.0481^{* * *}$ & 0.00 \\
\hline MARRIED & & & -0.0011 & 0.98 & & \\
\hline EDU & -0.0028 & 0.80 & $0.1365^{* * *}$ & 0.03 & 0.0059 & 0.28 \\
\hline EMP & & & $0.3830^{* * *}$ & 0.00 & & \\
\hline INC & $0.0001^{* *}$ & 0.04 & $0.0001^{* * *}$ & 0.00 & $0.0001^{*}$ & 0.06 \\
\hline GENDER & $-0.0615 * * *$ & 0.00 & $0.3911 * * *$ & 0.00 & $-0.3304 * * *$ & 0.00 \\
\hline RACE & & & & & $-0.0203^{* * *}$ & 0.00 \\
\hline NMBRADULT & 0.0144 & 0.03 & & & & \\
\hline NMBERKIDS & $-0.0144 * * *$ & 0.03 & & & & \\
\hline ANYDISEASE & -0.0212 & 0.13 & $-0.1732 * *$ & 0.03 & $0.0627 * * *$ & 0.00 \\
\hline DRADVICE & $0.2247^{* * *}$ & 0.00 & & & & \\
\hline SMOKES & & & & & $-0.0759^{* * *}$ & 0.00 \\
\hline DRINKS & & & & & $-0.0429 * * *$ & 0.00 \\
\hline SLEEP & & & $-0.0170^{* * *}$ & 0.00 & & \\
\hline HLTHCRFAC & & & & & -0.0001 & 0.29 \\
\hline RECREATION & & & $0.0247^{* * *}$ & 0.00 & & \\
\hline NORTH & & & $-0.4711^{* * *}$ & 0.00 & & \\
\hline Intercept & -4.5919 & 0.00 & 20.0165 & 0.00 & 8.2741 & 0.00 \\
\hline
\end{tabular}

Number of Observations $=7,267$.

$\mathrm{R}^{2}$ value: $\mathrm{CIT}=0.17 ; \mathrm{PAC}=0.55 ; \mathrm{BMI}=0.54$.

$\mathrm{Chi}^{2}$ value: $\mathrm{CIT}=628.83 ; \mathrm{PAC}=714.35 ; \mathrm{BMI}=1023.13$

***, **, * are significant at $1 \%, 5 \%$ and $10 \%$ respectively.

\section{Conclusions and Policy Suggestions}

One potential way of controlling obesity is changing behaviors of individuals. This was examined using a system of simultaneous equations with the endogenous variables of $\mathrm{BMI}$, the decision to reduce energy intakes (CIT) and time spent in physical activity (PAC).

Overall, results show that people with a high BMI value are more likely to reduce energy intakes but less likely to spend time on physical activity. Thus, policy attempts on reduce energy intakes would be more practical to control weight gain among obese adults. This needs to be linked with availability of food, food varieties, and market facilities too. However, results indicate the potential of weight gain control through physical activity. Thus, launch programs with more recreational facilities and activities to overcome sedentary life styles would be benefited especially for the adults with less BMI values.

The males are less likely to reduce energy intakes but prefer to engage in more physical activity. According to the sample 38 percent of the adults are male. Thus, programs for more facilities and opportunities for men to engage in exercise are essential in overcoming obesity in Appalachia. As women are more likely to reduce obesity by cutting down energy than by engaging in physical activity educating them to do that more efficiently would 
yield better results. However, they should be motivated to engage in physical activity too. The education and employment seem to be key factors of physical activity and energy intakes. Thus, policies to invest more on improved educational facilities and job creation would help in reducing obesity in long run.

The role of the healthcare professionals affect significantly on energy intakes decision of adults. This implies the potential of health professionals in controlling obesity by reducing energy intakes. Further, obesity related diseases reduce physical activity while increasing BMI, and controlling these diseases is important in controlling obesity. Thus, any policy attempt to overcome obesity by more physical activity and less energy intakes needs to address these issues.

\section{References}

[1] World Health Organization. Risk factor projects. (2005). Overweight and obesity, 2005. Retrieved from http://www.who.int/mediacentre/news/releases/2005/pr44/en/inde x.html

[2] Rossner, S. Obesity: The disease of the twenty-first century. International Journal of Obesity and Related Metabolic Disorders, 26(4), S2-S4, 2002.

[3] Sabate, J. and Wien, M. Vegetarian diets and childhood obesity prevention. American Journal of Clinical Nutrition, 9(suppl), 1525s-1529s, 2010.

[4] Finkelstein, E., Trogdon, J., Cohen, J.W. and Dietz, W. Annual medical spending attributable to obesity: Payer-and service specific estimates. Health Affairs, 28(5): 822-831, 2009.

[5] Dor, A., Ferguson, C., Langwith, C., and Tan, E. A heavy burden: The individual costs of being overweight and obese in the United States. Research Report. Department of Health Policy, School of Public Health and Health Services, The George Washington University, 2010.

[6] CDC. Overweight and obesity: U.S. obesity trends. 2010. Retrieve from http://www.cdc.gov/obesity/data/trends.html

[7] National health and nutritional examination survey (NHANES). 2009. Retrieved from

http://www.cdc.gov/nchs/nhanes/nhanes2009-

2010/nhanes09_10.htm

[8] Sturm, R., Ringel, J.S., and Andreyeve, T. Increasing obesity rates and disability trends, Health Affairs, 23(2), 199-205, 2004.

[9] Malnick, S.D.H., and Knobler, H. The medical complications of Obesity, QJM 99(9): 565-579. 2006.

[10] Miljkovic, D., and Nganje, W. (2008). Regional Obesity determinants in the United States: A model of myopic addictive behavior in food consumption. Agricultural Economics, 38, 375384, 2008.

[11] Chopra, M., Galbraith, C. and Darnton-Hill, I. A global response to a global problem: The epidemic of overnutrition. Bull World Health Organization, 80, 952-958, 2002.

[12] Rosin, O. The economic causes of obesity: A survey. Journal of Economic Survey, 22 (4), 617-647, 2008.

[13] Hammond, R.A. and Levine, R. The economic impacts of obesity in the United States: Diabetes, Metabolic Syndrome and Obesity. Targets and Therapy, 3, 285-295, 2010.

[14] CDC. Trends in intake of energy and macro-nutrients- United States. Morbidity and Mortality Weekly Reports, 5, 80-82. 2004.

[15] U.S. Department of Health and Human Services. The Surgeon General call to action to prevent and decrease overweight and obesity. Rockville, MD: U.S. Department of Health and Human Services, Office of Surgeon General, 2010.
[16] Cawley, J., Meyerhoefer, C. and Newhouse, D. The impacts of state physical education requirements on youth physical activity and overweight. NBER Working Paper 11411. 2005.

[17] Sacerdote, B. How large are the effects from changes in family environment? A study of Korean American adoptees. Quarterly Journal of Economics 122 (1), 119-158, 2007.

[18] Inagmi, S., Cohen, D.A., Finch, B.K. and Asch, S.M. You are where you shop: Grocery store locations, weight and neighborhoods. American Journal of Preventive Medicine, 31(1), 10-17, 2006.

[19] Wang, M C., Kim, S., Gonzalez, A.A., Macleod, K.E. and Winkleby, M.A. Socioeconomic and food related physical characteristics of the neighborhood environment are associated with body mass index. Journal of Epidemiology Community Health, 6, 491-498, 2007.

[20] National Institute of Health. National Heart Lung and Blood Institute. Clinical guidelines on the identification, evaluation and treatment of overweight and obesity in adults: the evidence report. Obes Res. 1998; 6: 51S-209S.

[21] Appalachian Regional Commission [ARC].The Appalachian Region.2010. Retrieved from

http://www.arc.gov/appalachian_region/TheAppalachianRegion.as

[22] Appalachian Regional Commission [ARC]. Economic Overview of Appalachia 2011. Retrieved from http://www.arc.gov/images/appregion/Sept2011/EconomicOvervie wSept2011.pdf.

[23] Appalachian Regional Commission [ARC]. Economic Assessment of Appalachia. An Appalachian Development Initiative Report. 2010. Retrieved from

http://www.arc.gov/images/newsroom/publications/EconomicAsse ssmentofAppalachiaJune2010.pdf.

[24] Wewers, M.R., Katz, M., Paskett, E.D. and Fickle, D. Risky behaviors among Ohio Appalachian adults. Preventive Chronic Disease, 3(4), A127, 2006.

[25] CDC. Morbidity and Mortality Weekly Report, 58, 45.2009. Retrieved from www.cdc.gov/mmwr.

[26] Touray, M.M.L., Research on obesity - time to think about the next agendas. Prog Health Sci, 3(2): 40-52, 2013.

[27] Becker, G. A Theory of the Allocation of Time. The Economic Journal, 75, 493-517. 1965.

[28] Zellner, A. and Theil, H. Three-Stage Least Squares: Simultaneous estimation of simultaneous equations. Econometrica,. 30 (1), 54-78, 1962.

[29] CDC. Behavioral Risk Factor Surveillance System Survey Data. U.S. Department of Health and Human Services, Atlanta, Georgia. 2009.

[30] Bureau of Economic Analysis [BEA], Regional Economic Accounts. 2009. Retrieved from http://www.bea.gov/regional/gdpmap/GDPMap.aspx

[31] U.S. Census Bureau, State and County Quick Facts, (2010). Retrieved from http://quickfacts.census.gov/qfd/states/54000.html

[32] STATA 9.1. Statistical/Data Analysis. http://www.stata.com.

[33] Nayga, R.M. Schooling, health knowledge and obesity, Applied Economics 32, 815-822, 2000.

[34] Drewnowski, A. and Specter, S. Poverty and Obesity: The role of energy density and energy costs. American Journal of Clinical Nutrition, 79, 6-16, 2004.

[35] Amarasinghe, A., D’Souza, G., Brown, C., Oh, H. and Borisova, T. The Influence of Socioeconomic and Environmental Determinants on Health and Obesity: A West Virginia Case Study. International Journal of Environmental Research and Public Health, 6, 22712287. 2009.

[36] Herath, J., Brown, C. and Hill, D. Economics of adult obesity and diabetes in Appalachia, Health,5(12), 2128-2136. 2013.

[37] Herath, J., Gebremedhin, T. and Fletcher, J. Adult Obesity and Arthritis: An Empirical Analysis for West Virginia, USA, International Journal of Health Research and Innovation 1(2) 1-12. 2013. 